\title{
PELAKSANAAN PEMBIAYAAN MURABAHAH SEKTOR MIKRO PADA PT. BANK BRI SYARIAH CABANG PADANG
}

\author{
Nurhikmah \\ Dosen Program Studi Hukum Ekonomi Syariah Jurusan Syari'ah \\ Sekolah Tinggi Agama Islam Negeri Batusangkar
}

\begin{abstract}
In this qualitative study, the researcher analyzed the implementation of micro sector of murabahah financing in PT Bank BRI Syariah Padang Branch. The findings revealed that the information which was received by the customer uncompleted, the customer did not understand the content of murabahah. The negotiation both customer and the bank were not done well. Every transaction, the bank gave the highest margin and the margin was determined by the bank. This concept was not related to the principle of An-Tarradin Minkum.
\end{abstract}

Kata Kunci: Micro Sector, Murabahah, Bank Syariah

\section{PENDAHULUAN}

Bank berdasarkan prinsip syariah berfungsi sebagai suatu lembaga intermediasi yaitu penghimpunan dana dari masyarakat dan menyalurkan kembali kepada masyarakat yang membutuhkannya dalam bentuk pembiayaan. Kegiatan usahanya tidak berdasarkan bunga (interest free), tetapi berdasarkan prinsip syariah, yaitu prinsip pembagian keuntungan dan kerugian (Perwataatmadja, 1992: 1).

Pembiayaan berdasarkan prinsip syariah adalah penyediaan uang atau tagihan yang dipersamakan dengan itu berdasarkan persetujuan atau kesepakatan antara bank dengan pihak lain yang mewajibkan pihak yang dibiayai untuk mengembalikan uang atau tagihan tersebut setelah jangka waktu tertentu dengan imbalan atau bagi hasil (Karim, 2009: 113). Lembaga perbankan yang diatur dalam syariah Islam adalah bagian muamalah yang mengatur hubungan antara sesama manusia (Pradjoto and Associates, 2010: 233).

Pada umumnya pembiayaan sektor mikro sudah ada pada produk pemasaran bank, yaitu Bank Umum Konvensional, Bank Umum Syariah dan Unit Usaha Syariah. Pada PT. Bank BRI Syariah Cabang Padang dibuat suatu unit untuk mengelola dan mengembangkan pembiayaan untuk usaha mikro kecil dan menengah yang dinamakan dengan Unit Mikro Syariah (UMS) (Pradjoto and Associates, 2010: 234).

Peresmian PT. Bank BRI Syariah Cabang Padang dimulai pada tanggal 15 
Januari 2004 di Jakarta yang merupakan Cabang ke-11 PT. Bank BRI Syariah dengan cabang pemasaran Sumatera Barat. Yang ditanda tangani oleh bapak Rudjito selaku Direktur Utama dan bapak Krisna Wijaya selaku Direktur PT. BRI (persero tbk).

PT. Bank BRI Syariah Cabang Padang berlokasi di Jalan Veteran No. 37 di Padang yang dibatasi oleh Jalan Raya Veteran (bagian depan), KIA Motor bersebelahan langsung pada posisi kanan) dan areal pemukiman penduduk di sebelah kiri (Wawancara dengan Irfan Sopandi, Sales Officer, PT. Bank BRI Syariah Cabang Padang Tanggal 01 Maret 2014). Fokus penelitian ini adalah mengetahui bagaimana pelaksanaan pembiayaan murabahah sektor mikro pada unit mikro syariah PT. Bank BRI Syariah Cabang Padang.

\section{LANDASAN TEORI}

\section{Jual Beli Tauliyah (بيع التولية)}

Jual beli tauliyah adalah membeli dengan harga yang sama dengan modal penjual.

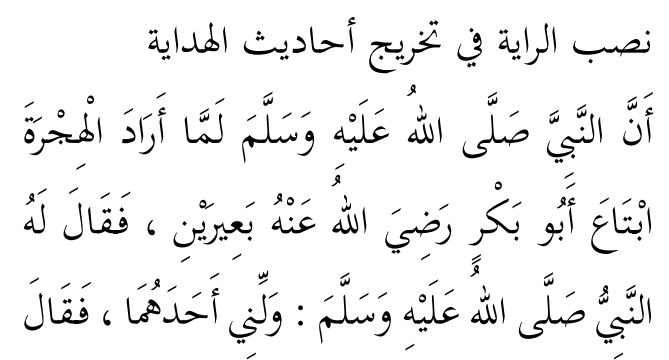

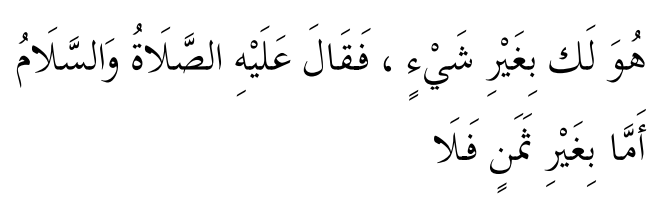

"bahwa ketika Rasulullah saw akan melaksanakan hijrah, Abu Bakar ra membeli dua ekor onta, lalu Rasulullah saw berkata padanya, "Juallah salah satu dari onta itu kepada saya secara tauliyah". Abu Bakar menjawab, "Onta itu aku berikan pada Anda tanpa imbalan apapun," maka Rasulullah saw menjawab lagi, "Jika dengan tanpa harga, maka saya tidak mau." (HR. Abdurrazzaq)

Kebolehan jual beli tauliyah disepakati oleh para ulama karena 1) ia memenuhi semua syarat jual beli sehingga semua akibat hukum jual beli sempurna melekat padanya, 2) karena masyarakat biasa melakukan akad ini dari dulu sampai sekarang, dan 3) sesuai dengan kebutuhan (hâjah) manusia dalam bidang bisnis.

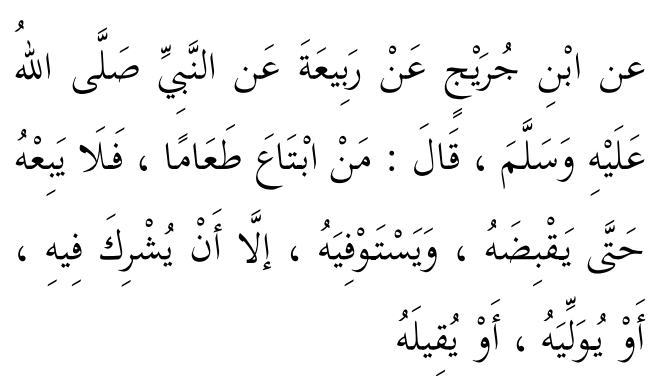

Dari Ibnu Juraij, dari Rabi'ah, telah bersabda Rasulullah saw: "Barangsiapa yang membeli suatu makanan, hendaklah ia tidak menjualnya kembali sehingga ia menggenggamnya (alqabdh) dan menggenggamnya secara penuh (yastaufiyahu) kecuali jika ia melakukan isyrâk atau tauliah atau iqâlah (Mushannaf Abdurrazaq) (HR. Abdurrazzaq). 
2. Jual Beli Wadhi'ah (ليع الوضيعة/Resale At A Loose)

Terkadang jual beli wadhi'ah disebut juga dengan jual beli alhathîthah (بيع الحطيطة) atau jual beli annaqîshah (بيع النيصة). Secara ringkas jual beli wadhi'ah adalah penjualan dengan harga dibawah harga pembelian. Sedangkan secara definitif, ia adalah suatu jual beli dimana harga sudah ditentukan lebih rendah atau kurang dari modal pembelian atas barang.

Jika Ahmad berkata pada Husain "saya telah membeli printer baru ini seharga Rp. 1 juta rupiah, dan karena sedang memerlukan uang tunai (atau karena kamu teman saya), sekarang saya jual pada Anda dengan harga Rp. 900 ribu." Jual beli seperti ini dinamakan dengan jual beli wadhi'ah. Atau juga dapat dengan menyatakan, "Saya menjualnya pada Anda dengan 90\% harga pembelian," atau, "Saya merugikan diri saya Rp. 100 ribu darinya".

\section{Jual Beli Amanah}

Pada dasarnya jual beli ini dibangun atas prinsip saling percaya dan amanah. Hukum untuk kasus khianat pada jual beli amanah, dikembalikan kepada masing-masing kasus. Artinya hukumnya berbeda-beda sesuai dengan kasusnya. a. Khianat dalam transaksi murabahah dan tauliyah

Bentuk khianat dalam transaksi murabahah atau tauliyah ada dua kemungkinanan antara lain sebagai berikut.

1) Khianat dalam cara pembayaran. Misalnya A membeli motor secara kredit seharga 10 juta, kemudian dia memberi tahu B bahwa A membeli motor ini 10 juta, namun tidak kreditnya dia rahasiakan. Jika B mau beli maka harganya 11 juta tunai. Beberapa hari setelah transaksi B baru mengetahui bahwa motor itu kredit. Dalam kasus semacam ini, B memiliki hak untuk memilih berdasarkan kesepakatan ulama. Dia berhak untuk melanjutkan dan menghentikan transaksi. Karena transaksi murabahah dibangun atas prinsip amanah. Pembeli telah menaruh kepercayaan kepada penjual tentang informasi harga yang dia berikan. Sehingga jika syarat amanah dalam jual beli ini tidak terpenuhi maka ada hak khiyar. 
2) Khianat dalam informasi harga Misalnya A membeli HP seharga 500.000. Kemudian dia memberi tahu B bahwa dia beli HP tersebut 700.000. Si B boleh membeli HP ini jika dia membayar 700.000, dengan harapan agar B beranggapan bahwa A tidak mengambil untung Hpnya. Setelah beberapa hari, B baru sadar bahwa aslinya dia membeli HP tersebut 500.000 bukan 700.000. Dalam kasus semacam ini, ulama berbeda pendapat dalam hukumnya:

a) Syafi iyah, Hambali, dan Imam Abu Yusuf berpendapat bahwa pembeli tidak memiliki hak khiyar. Namun dia mengambil jatah karena khianat.

b) Abu Hanifah mengatakan: bahwa pembeli memiliki hak khiyar. Dia boleh mengambil seluruh uang yang dia bayarkan (membatalkan transaksi). Namun untuk jual beli tauliyah, tidak ada hak khiyar untuk pembeli. Dia boleh mengurangi harga barang sebatas khianatnya dan dia beli dengan harga sisanya.

c) Muhammad bin Hasan dan pendapat lain dalam mazhab Syafi iyah, bahwa jika terjadi khianat dalam informasi harga, pembeli memiliki hak khiyar untuk transaksi murabahah maupun tauliyah.

3) Khianat dalam transaksi mustarsal. Bentuknya, misalnya sesuai perjanjian untuk dijual sesuai harga pasar, ternyata dia dibohongi dengan harga yang lebih tinggi dari umumnya masyarakat maka pembeli memiliki hak khiyar.

\section{Surat Berharga Dalam Pandangan} Fiqh Muamalah

Terdapat dua surat dalam pernyataan hutang yang terkenal dalam sejarah ekonomi islam, yaitu syak (dalam bentk jamaknya: shukuk) dan suftajah (bentuk jamaknya: syafatij). Kegiatan surat utang syak dan suftajah berkaitan erat dengan profesi sharrafah. Shairafi atau sharraf adalah sebutan bagi orang berprofesi dalam bidang shairafah atau sharrafah, maka melakuakan shairrfah berarti melakukan kegiatan 
yang berhubungan dengan shairrafiy atau sharraf seperti penukaran uang dan transfer uang. Kegiatan syairrafah hampir sama dengan peranan bank pada zaman modern.

Pemakaian istilah sukuk modern terkait dengan istilah yang berlaku pada zaman klasik islam dimana sukuk mempunyai pengertian umum "surat pernyataan sebuah kontrak, laporan, dan data-data tuntutan dalam pengadilan" (Alimin, 2010: 34). Namun demikian dalam bidang fiqh muamalat, sukuk lebih dikenal dengan surat pernyatan hutang, kewajiban atas pihak yang tertuju pada surat tersebut atau surat bukti terhadap suatu hak. Sejak masa Khalifah Umar Bin AL-Khatab, sukuk sudah mempunyai stempel disamping nama atau tanda tangan pembuatnya.

Sukuk diakui oleh para fuqaha sebagai bukti penguat keyika terjadi sengkleta harta benda dan kadang kala dapat dijadikan sebgai bukti mutlak. Pemalsuan sukuk atau pembuat sukuk palsu guna mendapatkan suatu harta benda secara batila dikenakan hukuman ta'zir, sebagaimana umar ibn Al-Khatab menjatuhkan hukuman 300 kali cambuk dan pembuangan atas orang yang memalsukan stempel Baitul Mal guna mendapatkan harta. Susku keuangan boleh di titipkan dan di akui secara hukum wadiah (Kementrian Kuwait, 2006: 6).

\section{METODE PENELITIAN}

Dalam penelitian ini metode penelitiannya adalah metode penelitian kualitatif. Penelitian ini 1) dilaksanakan pada kondisi yang alamiah; 2) lebih bersifat deskriptif, sumber data utama dalam penelitian kualitatif adalah kata-kata dan tindakan, selebihnya adalah data tambahan seperti dokumen atau bahan lain (Moleong, 2007: 157), sehingga tidak menekankan pada angka; 3) lebih menekankan pada proses daripada produk atau outcome; 4) analisis data dilakukan secara induktif; dan 5) lebih menekankan makna (data dibalik yang teramati) (Sugiyono, 2007: 9). Data yang dikumpulkan dalam penelitian ini adalah berupa kata-kata dan kalimat yang merupakan hasil interview, observasi dan dokumentasi.

Teknik observasi yang digunakan dalam penelitian ini untuk menggali data dari sumber data yang berupa peristiwa, tempat atau lokasi dan benda serta rekaman gambar (Sutopo, 2002: 64). Teknik wawancara yang digunakan dalam penelitian ini adalah teknik wawancara tidak terstruktur (in-depth interviewing) karena peneliti merasa" tidak tahu apa yang 
belum diketahuinya". Dengan demikian wawancara dilakukan dengan pertanyaan yang bersifat "open-ended", dan mengarah kepada kedalaman informasi (Sutopo, 2002: 59) dari data primer. Studi dokumen dilakukan dengan penelitian mengenai dokumen-dokumen yang berkaitan dengan penerapan pembiayaan murabahah di PT. Bank BRI Syariah Cabang Padang. Dokumen sudah lama digunakan dalam penelitian sebagai sumber data karena dalam banyak hal dokumen sebagai sumber data dimanfaatkan untuk menguji, menafsirkan, bahkan untuk meramalkan (Moleong, 2007: 217).

Menurut Khusnin (2006: 26), penelitian kualitatif memuat beberapa cara untuk meningkatkan kesahihan data penelitian, yaitu triangulasi data, pengecekan dengan anggota atau member check, penyusunan database dan penyusunan mata rantai semua bukti penelitian. Penelitian ini menggunakan triangulasi data, menurut Moleong (2007: 331) triangulasi metode dilakukan dengan dua strategi antara lain, 1) pengecekan derajat keterpercayaan penemuan hasil penelitian beberapa teknik pengumpulan data yang sama, dan 2) pengecekan derajat keterpercayaan beberapa sumber data dengan metode yang sama. Triangulasi data yang dilakukan dalam penelitian ini adalah membandingkan hasil yang diperoleh melalui wawancara dengan data yang diperoleh melalui dokumentasi

Teknik analisis data yang digunakan dalam penelitian ini adalah analisis data kualitatif, mengikuti konsep yang diberikan Miles dan Huberman. Miles dan Huberman mengemukakan bahwa aktivitas dalam analisis data kualitatif dilakukan secara interaktif dan berlangsung secara terus menerus pada setiap tahapan penelitian sehingga sampai tuntas, dan datanya sampai jenuh (Moleong, 2007: 307).

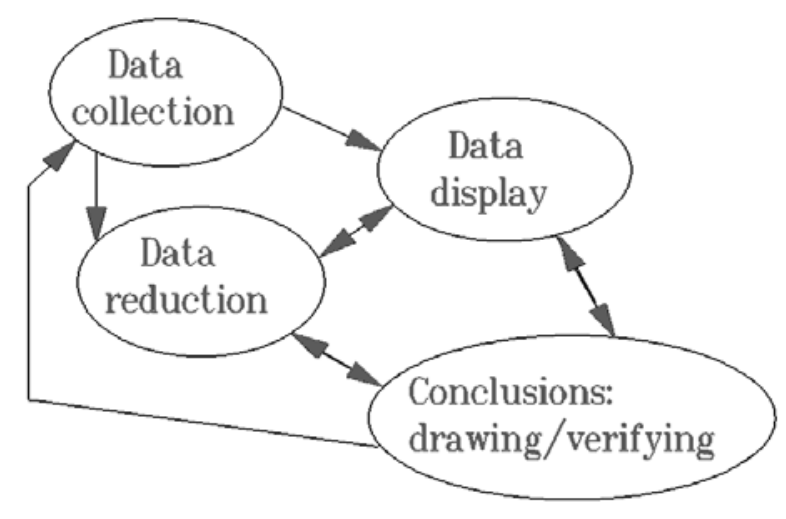

Figure: M\&H's Components of Data Analysis

Model analisis interaktif Miles dan Huberman, (1994)

\section{HASIL PENELITIAN DAN PEMBAHASAN}

Penerapan pembiayaan murabahah yang menggunakan sistem murabahah ini bisa dikatakan merupakan hybrid contract yang ada pada pembiayaan mikro ini karena di dalamnya menggabungkan dua akad dalam satu transaksi yakni akad murabahah dan akad wakalah, tetapi di 
dalam pelaksanaanya masih terdapat ketidaksesuaian, pada saat proses akad murabahah pihak bank telah memberikan sejumlah uang untuk dipergunakan oleh nasabah membeli barang yang diinginkan nasabah, selanjutnya ketika nasabah telah membeli barang tersebut, nasabah hanya perlu untuk memberikan kwitansi atau bukti pembayaran kepada pihak bank dan diberi jangka waktu 1 minggu untuk menyerahkan bukti pembelian atas barang kepada bank (Wawancara dengan Yan Aprizal, Sales Officer PT. Bank BRISyariah Cabang Padang Senin, Tanggal 03 Juni 2014).

Berdasarkan wawancara yang peneliti lakuakan, dalam transaksi ini pihak bank selalu memberikan margin yang tertinggi untuk setiap transaksinya, ternyata hal ini dilakukan oleh pihak bank untuk mencari keuntungan dan untuk menghindarai resiko kerugian (Wawancara dengan Erik Estrada, Area Financing Officer, Senin, 30 Juni 2014). Sebagaimana data yang peneliti temukan mengenai plafon pembiayaan murabahah sektor mikro dan besar margin yang ditentukan adalah sebagai berikut.

Tabel: Fitur Produk Pembiayaan Sektor Mikro PT. Bank BRI Syariah Cabang Padang (Dokumen Pembiayaan Murabahah Sektor Mikro pada PT. Bank BRI Syariah Cabang Padang)

\begin{tabular}{|l|l|l|l|}
\hline \multicolumn{1}{|c|}{ Produk } & \multicolumn{1}{c|}{ Pagu (juta) } & \multicolumn{1}{c|}{ Tenor } & \multicolumn{1}{c|}{ Margin } \\
\hline Mikro 25iB & $5-25$ & $6-36$ bulan & $2,13-2,28 \%$ \\
\hline Mikro 75iB & $5-75$ & $6-36$ bulan & $1,68-1,44 \%$ \\
\hline Mikro 500iB & $>75-500$ & 5-36 Bulan & $1,53-0,94 \%$ \\
& & $\begin{array}{l}5-48 \text { Bulan } \\
\text { 5-60 Bulan }\end{array}$ & \\
\hline
\end{tabular}

Pada tahap berikutnya yaitu pada tahap pencairan dana atau tahap penandatangan akad, nasabah diberikan form perjanjian yang telah disediakan oleh bank yang berisi pasal-pasal dan perjanjian yang dibuat oleh pihak bank dan bersifat memaksa, karena form tersebut telah disediakan dan tidak ada perbincangan dahulu sebelumnya mengenai pasal yang ada.

Mengenai kwitansi pembelian barang, pihak bank mewajibkan kepada setiap nasabah yang menggunakan pembiayaan sektor mikro untuk menyerahkan kwitansi atau bukti lain atas pembelian barang yang sesuai dengan permohonan pembiayaannya. Namun kepercayaan yang diberikan oleh pihak bank, bagi sebahagian nasabah ada juga yang tidak memegang amanah dari pihak bank. Berdasarkan penelitian yang dilakukan, peneliti menemukan ada sebahagian nasabah yang melakukan kecurangan dalam hal kwitansi tersebut dengan melakukan pemalsuan kwitansi dengan cara menyerahkan kwitansi yang tidak menggunakan stempel toko, faktur yang tidak memiliki tanda tangan.

Berdasarkan peristiwa ini dapat diambil kesimpulan bahwa telah terjadi khianat wakalah dari pihak nasabah terhadap pihak bank, selanjutnya bagi nasabah telah terjadi pelanggaran akad sehingga akad 
murabahah tidak terjadi tetapi termasuk kepada akad hutang piutang. Sementara dari pihak bank, bank tidak disalahkan dalam akad ini selama bank benar- benar tidak mengetahui pelanggaran tersebut dan bank dapat dikategorikan sebagai pihak yang dirugikan dalam akad ini.

Namun apabila bank merasa yakin dengan pemalsuan tersebut berarti kedua belah pihak sama-sama khianat dalam pelaksanaan akad murabahah yang selanjutnya berarti bahwa tidak ada akad murabahah yang mereka laksanakan tetapi hanya hutang piutang dan laba tertentu yang sama kedudukannya dengan riba. Secara hukum ekonomi syariah seharusnya pihak bank melakukan tabayun (mengkonfirmasi) bahwa akad benar-benar dilaksanakan dengan baik.

Berdasarkan analisis peneliti memang akad wakalah sudah terjadi karena pihak bank sudah meminta bukti berupa kwitansi, walaupun akad wakalah ini tidak dijelaskan secara tertulis di dalam akad. Secara substansi prosedur jual beli ke supplier oleh bank sudah terjadi melalui akad wakalah dengan nasabah.

Pembiayaan sektor mikro pada PT. BRI Syariah Cabang Padang telah memiliki standar penetapan pembiayaan seperti yang sudah peneliti jelaskan di atas, pembiayaan ini khusus disalurkan kepada nasabah yang memiliki usaha mikro, kecil dan menengah, namun berdasarkan penelitian dan wawancara yang peneliti lakukan ternyata pihak bank lebih mementingkan dan menomor satukan nasabah yang mengajukan permohonan pembiayaan mikro dengan nilai jaminan yang tinggi. Seperti jaminan berupa sertifikat tanah, bangunan dan kendaraan roda empat, sedangkan untuk usaha mikro dan kecil pihak bank kurang begitu memperhatikan sedangkan tujuan utamanya dari pembiayaan mikro ini adalah untuk memberdayakan usaha mikro, kecil dan menengah (Wawancara dengan Deby Cecylia, Mikro Banking Group, Tanggal 08 Maret 2014).

\section{KESIMPULAN}

Kesimpulan yang didapatkan dari hasil penelitian mengenai pelaksanaan pembiayaan murabahah sektor mikro pada PT. Bank BRI Syariah Cabang Padang adalah nasabah datang dengan segala kontrak yang sudah dibuat oleh pihak bank karena isi di dalam form perjanjian akad murabahah lansung diberikan kepada nasabah, namun belum dijelaskan secara rinci oleh pihak bank, jadi dapat peneliti simpulkan bahwasanya informasi yang diterima oleh nasabah tidak sepenuhnya 
dipahami dan dimengerti oleh pihak nasabah yang melakukan transaksi pada pembiayaan murabahah sektor mikro. Selain itu negosiasi yang berlangsung antara nasabah dan pihak bank belum sempurna dilakukan karena pihak bank dalam setiap transaksi yang dilakukan selalu memberikan margin yang tertinggi, hal ini dilakukan oleh pihak bank dengan alasan untuk menghindari resiko kerugian. Margin juga ditentukan oleh pihak bank tentunya hal ini tidak sejalan dengan prinsip An-Tarradin Minkum.

\section{KEPUSTAKAAN ACUAN}

Alimin. (2010). Aplikasi Pasar Sukuk Dalam Perspektif Syariah (Studi Analisis Kesesuaian Syariah Terhadap Aplikasi Pasar Sukuk Domestik dan Global.

Karim, Adiwarman A. (2009). Bank Islam Analisis Figh dan Keuangan. Jakarta: PT. Raja Grafindo Persada.

Kementrian Kuwait. (2006). Al-Mausu'ah al-Fiqiyah Al-Quwatiyah. Kuwait: Kementrian Perwakafan Kuwait
Khusnin, Muh. (2006). Pengelolaan Sekolah Berdasarkan Sekolah Standar Nasional (SSN), Studi Kasus Pada Sekolah Menengah Pertama Negeri 2 Cepu. Surakarta: Tesis UMS

Miles, Mathew B \& Huberman, A. Michael. (1994). Qualitative Data Analysis. An Expanded Sourcebook Second Edition. Thousand Oaks, CA: Sage.

Moleong, Lexy, J, (2007). Metodologi Penelitian Kualitatif. Bandung: PT. Remaja Rosdakarya

Perwataatmadja, Karnaen (1992). Apa dan Bagaimana Bank Islam. Yogyakarta: PT. Dana Bakti Prima Yasa.

Pradjoto and Associates. (2010). Pembiayaan dalam Perbankan Syariah. Jakarta: PT. Raja Grafindo Persada.

Sugiyono. (2007). Memahami Penelitian Kualitatif. Bandung: CV. ALFABETA Sutopo, HB. (2002). Metodologi Penelitian Kualitatif. Surakarta: UNS Press 